\title{
LAPAROSCOPIC MANAGEMENT OF SUSPICIOS ADENEXAL MASS
}

\author{
By \\ Ibrahim Safwat Ibrahim, Esmail T. El-Garhy and Maged M.Labib* \\ Department Obstetrics \& Gynecology, Faculty of Medicine, Al-Azhar University \\ Corresponding author: Ibrahim Safwat Ibrahim, \\ E-mail: dribrahimelqtaly89@gmail.com
}

\begin{abstract}
Background: Different tools have been used for prediction of malignancy in ovarian masses; such as tumor markers, ultrasound findings, or other malignancy indices combining more than one variable. Cancer antigen 125 (CA-125) is the most frequently used biomarker for ovarian cancer detection.

Objective: To investigate whether laparoscopy could replace safe and effective surgical management of adnexal masses.

Patients and Methods: This was a prospective study. It was conducted over 2 years in Al-Maadi Military Hospital and Air force General Hospital. The study was conducted on 100 patients from October 2018 till September 2020. Histopathology was done by Histopathology team at Maadi Military hospital.

Results: All 93 patients managed laparoscopically had a benign and malignant diagnosis, whereas 7 of the 19 patients who underwent laparotomy were diagnosed with malignancy. The indications for conversion to laparotomy were malignancies, dense adhesions and small bowel enterotomies.

Conclusion: Laparoscopic surgery seemed to offer significant advantages such as reduced hospital stay, less adverse effects, and better quality of life, laparoscopic surgery became a corner stone in management of adenexal masses either benign or malignant especially if the facility of Frozen Section Biopsy can be offered.
\end{abstract}

Keywords: Adenexal Mass, Laparoscopic, Ovarian cancer.

\section{INTRODUCTION}

Over years, laparoscopy has evolved from a limited gynecologic surgical procedure used only for diagnosis and tubal ligations to a major surgical tool used for management of a variety of gynecological conditions. Today, laparoscopy has emerged as one of the most common surgical procedures. The faster recovery time, minimal pain, fewer days of hospitalization and better aesthetic results has made laparoscopy immensely popular. Also, technical parameters such as the magnified view during the procedure and relatively small risk of complications resulted in the wide use of laparoscopic surgery in gynecology. Laparoscopy has now become the gold standard method for management of a wide range of gynecological ailments, including the adnexal masses. Although, most of the adnexal masses arise from ovaries, a wide variety of pathologies may be associated. Tuboovarian abscess, ectopic pregnancy, subserosal fibroids with pedicle, appendicular mass etc. are the common pathologies that need to be differentiated (Zaman et al., 2010). 
IBRAHIM SAFWAT IBRAHIM et al.,

A number of non-neoplastic and neoplastic lesions occur within the ovaries. They can present from the neonatal period to post-menopause. Most are functional in nature and resolve with minimal treatment. However, ovarian cysts can herald an underlying malignant process. When cysts are large, persistent, or painful, surgery may be required (Matsushita et al., 2014). The sonological detection of ovarian malignancy is quite good and acceptable. The predictive value is about $96 \%$ in detection of the benign masses (Karnik et al., 2015).

The procedure, being non-invasive, is widely acceptable for establishing the diagnosis. Magnetic resonance imaging (MRI) increases the specificity of imaging evaluation for adnexal masses, especially when they are indeterminate on ultrasound (Grammatikakis et al., 2015).

MRI has a high accuracy in differentiating benign from malignant masses. Endometriomas, Teratomas, simple cysts, fibromas, exophytic or extrauterine fibroids, and hydrosalpinges can be diagnosed with high specificity. Histopathological and MRI correlation of adnexal masses, the role of MRI in the differentiation of benign from malignant adnexal pathologies, is found to quite promising. Magnetic resonance imaging is useful in characterization of adnexal masses that are not completely evaluated by ultrasound. It can provide valuable information on soft tissue composition based on specific tissue relaxation times and allows multiplanar imaging at large field of view to define the origin and extent of pelvic pathology (Karnik et al., 2015).
The aim of this study was to investigate laparoscopy in surgical management of adnexal masses.

\section{PATIENTS AND METHODS}

This is a prospective study. It was conducted over 2 years in Al Maadi Military Hospital and Air force General Hospital, the study was conducted on 100 Patients, all cases were operated on selective basis. The study carried out during the period between October 2018 till September 2020.

Inclusion criteria was, female patients aged above (9 years old), preoperative estimation of the tumor markers levels especially CA 125 (normal range 0-35 $\mathrm{mU} / \mathrm{L}), \mathrm{u}$. In cases of doubt, MRI with or without contrast was done to establish the exact nature of the masses.

Exclusion criteria were known contraindications for laparoscopy, such as medical reasons, preoperative abdomens caused by adhesion formation, coagulopathy, cirrhosis, aberrant anatomy, small bowel obstruction, disseminated abdominal cancer, pulmonary compliance and cardiovascular issues, and intracranial disease.

Trans-vaginal ultrasound scanning was used as primary imaging. After written informed consents, all the patients were taken for the procedures under general anesthesia. Preoperative findings were noted. All patients underwent careful bowel preparations. The facility of frozen section biopsy is available in our hospital. All the specimens were sent for histopathological examinations post operatively. All the patients received a single dose IV ceftriaxone and sulbactum (1.5 gm) preoperatively and 3 days oral 
antibiotic (200 mg cefixime) for next 5 days, except in complicated cases. In complicated cases, they were individualized for antibiotic protocol. Study was approved by the ethical committee of the hospital. Histopathology was done by Histopathology team at Maadi Military hospitaly.

In our study, we compared the safety and effectiveness of laparoscopy versus laparotomy including preoperative demographic criteria (age, weight, height, BMI), intraoperative bleeding, postoperative hospital stay, and, complications.

All patients were subjected to the following: Written informed consent, thorough history, medical surgical, obstetrics, menstrual \& familial history, detailed history, and pre-anesthetic workup was done on all patients, physical examination; measurement of body mass index weight per meter square, general examination and investigations (Laboratory: CBC, viral markers Hepatic viral markers, Ca125, Ca19.9, CEA and
AFP. Vaginal Us, MRI on abd. and pelvis).

The used laparoscopic instruments were type Karl Stores.

Acknowledgment: especial thanks for the team of histopathology at Maadi Military Hospital for their precious help to complete the histopathology part of the study.

\section{Statistical analysis:}

Statistical analysis was done by SPSS v25 (IBM Inc., Chicago, IL, USA). Normality of data was checked with Shapiro-Wilks test. Numerical variables were presented as mean and standard deviation (SD) and compared between the two groups utilizing Student's t- test. Categorical variables were presented as frequency and percentage (\%) and were analysed utilizing the Chi-square test or Fisher's exact test when appropriate. $\mathrm{P}$ value $<0.05$ was considered significant.in statistical methods sections: utilizing independent t-test and Mann Whitney $\mathrm{U}$ test.

\section{RESULTS}

Mean \pm SD of age was $45.6 \pm 11.8$ years, of weight was $73.1 \pm 8.8 \mathrm{~kg}$, of height was $1.66 \pm 0.05 \mathrm{~m}$ and of BMI was 26.6 \pm 2.7 $\mathrm{kg} / \mathrm{m} 2$. post menopause was in $40.0 \%$ of cases. The most frequent clinical presentations were abdominal pain (67.0\%), followed by pelvic pain $(53.0 \%)$, then bleeding $(30.0 \%)$ and urinary (25.0\%) (Table 1). 
Table (1): Demographic characteristics and clinical presentations among the studied cases

\begin{tabular}{|c|c|c|c|}
\hline \multicolumn{2}{|l|}{ Variables } & Mean \pm SD & Range \\
\hline \multicolumn{2}{|l|}{ Age (years) } & $45.6 \pm 11.8$ & $18.0-71.0$ \\
\hline \multicolumn{2}{|l|}{ Weight (kg) } & $73.1 \pm 8.8$ & 50.9-94.5 \\
\hline \multicolumn{2}{|l|}{ Height (m) } & $1.66 \pm 0.0 .5$ & $1.51-1.78$ \\
\hline \multirow{2}{*}{\multicolumn{2}{|c|}{ BMI $\left(\mathrm{kg} / \mathrm{m}^{2}\right)$}} & $26.6 \pm 2.7$ & $18.7-34.3$ \\
\hline & & $\mathbf{N}$ & $\%$ \\
\hline \multirow{2}{*}{ Menopause } & Pre & 60 & 60.0 \\
\hline & Post & 40 & 40.0 \\
\hline \multicolumn{2}{|c|}{ Abdominal pain } & 67 & 67.0 \\
\hline \multicolumn{2}{|l|}{ Pelvic pain } & 53 & 53.0 \\
\hline \multicolumn{2}{|l|}{ Bleeding } & 30 & 30.0 \\
\hline \multicolumn{2}{|l|}{ Urinary } & 25 & 25.0 \\
\hline
\end{tabular}

Total=100. BMI: Body mass index.

The most frequent pathology was endometriosis $(34.0 \%)$, followed by serous cyst $(20.0 \%)$, then tubo-ovarian complex (13.0\%), dermoid cyst (13.0\%), hemorrhagic corpus luteum cyst $(9.0 \%)$, fibroids $(6.0 \%)$, ovarian cancer $(2.0 \%)$ and uterine cancer $(2.0 \%)$. Complications were in $(8.0 \%)$, whole ascites developed in $(4.0 \%)$. Mean \pm SD of hospital stay was $3.1 \pm 1.6$ days (Table 2).

Table (2): Pathological and postoperative findings among the studied cases

Total $=100$.

\begin{tabular}{|l|c|c|}
\hline Characteristics & $\mathbf{N}$ & \% \\
\hline Endometriosis & 34 & 34.0 \\
\hline Serous cyst & 20 & 20.0 \\
\hline Tubo-ovarian complex & 13 & 13.0 \\
\hline Dermoid cyst & 13 & 13.0 \\
\hline Hemorrhagic corpus luteum cyst & 9 & 9.0 \\
\hline Fibroids & 6 & 6.0 \\
\hline Ovarian cancer & 2 & 2.0 \\
\hline Uterine cancer & 2 & 2.0 \\
\hline Complications & 8 & 8.0 \\
\hline Ascites & 4 & 4.0 \\
\hline & Mean \pm SD & Range \\
\hline Hospital stay (days) & $3.1 \pm 1.6$ & $1.0-11.0$ \\
\hline
\end{tabular}

No significant differences according to laparotomy and laparoscopy regarding demographic characteristics. Age was $49.9 \pm 16.8$ and $45.3 \pm 11.4$ years respectively $\quad(p=0.325)$, weight was $70.4 \pm 7.9$ and $73.3 \pm 8.9 \mathrm{~kg}$ respectively $(\mathrm{p}=0.404)$, height was $1.65 \pm 0.04$ and $1.66 \pm 0.05 \mathrm{~m}$ respectively $(\mathrm{p}=0.783)$, BMI was $25.7 \pm 2.2$ and $26.6 \pm 2.7$ respectively $(\mathrm{p}=0.400)$, while postmenopausal was
$(57.1 \%)$ and (38.7\%) respectively $(\mathrm{p}=0.433)$.

No significant differences according to laparotomy and laparoscopy regarding clinical presentation. Abdominal pain was $(85.7 \%)$ and $(65.6 \%)$ respectively $(\mathrm{p}=0.420)$, Pelvic pain was $(57.1 \%)$ and $(52.7 \%)$ respectively $(\mathrm{p}=0.999)$, Pelvic Bleeding was $(57.1 \%)$ and $(28.0 \%)$ respectively $(\mathrm{p}=0.193)$ and Urinary was 
$(14.3 \%)$ and $(25.8 \%)$ respectively $(\mathrm{p}=0.677)$.

Operation duration was significantly longer in laparotomy than in laparoscopy; $229.3 \pm 89.0$ and $127.3 \pm 31.4 \quad(\mathrm{p}=0.023)$. Blood loss was significantly higher in laparotomy than in laparoscopy; $862.9 \pm 374.4$ and $267.7 \pm 75.8(\mathrm{p}<0.001)$.

Ovarian cancer was significantly more frequent in laparotomy than in laparoscopy; $(28.6 \%)$ and $(0.0 \%)$ respectively $(\mathrm{p}=0.004)$. Uterine cancer was significantly more frequent in laparotomy than in laparoscopy; (28.6\%) and $(0.0 \%)$ respectively $(\mathrm{p}=0.004)$.

Complications were significantly more frequent in laparotomy than in laparoscopy; (42.9\%) and (5.4\%) respectively $(\mathrm{p}=0.010)$. No significant differences according to laparotomy and laparoscopy regarding ascites; $(0.0 \%)$ and $(4.3 \%) \quad(\mathrm{p}=0.999)$. Hospital stay was significantly longer in laparotomy than in laparoscopy; $6.4 \pm 3.4$ and $2.8 \pm 0.2$ $(\mathrm{p}<0.001)$ (Table 3).

Table (3): Comparison according to performed intervention regarding demographic characteristics, clinical presentation, operative characteristics, pathological findings and postoperative findings.

\begin{tabular}{|c|c|c|c|c|}
\hline \multicolumn{2}{|l|}{ Variables } & $\begin{array}{c}\text { Laparotomy } \\
(\mathbf{N}=7)\end{array}$ & $\begin{array}{c}\text { Laparoscopy } \\
(\mathrm{N}=93)\end{array}$ & P-value \\
\hline \multicolumn{2}{|l|}{ Age (years) } & $49.9 \pm 16.8$ & $45.3 \pm 11.4$ & $>0.05$ \\
\hline \multicolumn{2}{|l|}{ Weight (kg) } & $70.4 \pm 7.9$ & $73.3 \pm 8.9$ & $>0.05$ \\
\hline \multicolumn{2}{|l|}{ Height (m) } & $1.65 \pm 0.04$ & $1.66 \pm 0.05$ & $>0.05$ \\
\hline \multicolumn{2}{|l|}{ BMI $\left(\mathrm{kg} / \mathrm{m}^{2}\right)$} & $25.7 \pm 2.2$ & $26.6 \pm 2.7$ & $>0.05$ \\
\hline \multirow{2}{*}{ Menopause } & Pre & $3(42.9 \%)$ & $>0.05$ & \multirow{2}{*}{$>0.05$} \\
\hline & Post & $4(57.1 \%)$ & $>0.05$ & \\
\hline \multicolumn{2}{|c|}{ Abdominal pain } & $6(85.7 \%)$ & $61(65.6 \%)$ & $>0.05$ \\
\hline \multicolumn{2}{|c|}{ Pelvic pain } & $4(57.1 \%)$ & $49(52.7 \%)$ & $>0.05$ \\
\hline \multicolumn{2}{|l|}{ Bleeding } & $4(57.1 \%)$ & $26(28.0 \%)$ & $>0.05$ \\
\hline \multicolumn{2}{|l|}{ Urinary } & $1(14.3 \%)$ & $24(25.8 \%)$ & $>0.05$ \\
\hline \multicolumn{2}{|c|}{ Duration (minutes) } & $229.3 \pm 89.0$ & $127.3 \pm 31.4$ & $\mathbf{0 . 0 2 3}$ \\
\hline \multicolumn{2}{|c|}{ Blood loss (mL) } & $862.9 \pm 374.4$ & $267.7 \pm 75.8$ & $<0.001$ \\
\hline \multicolumn{2}{|c|}{ Endometriosis } & $2(28.6 \%)$ & $32(34.4 \%)$ & $>0.05$ \\
\hline \multicolumn{2}{|c|}{ Serous cyst } & $0(0.0 \%)$ & $20(21.5 \%)$ & $>0.05$ \\
\hline \multicolumn{2}{|c|}{ Tubo-ovarian complex } & $0(0.0 \%)$ & $13(14.0 \%)$ & $>0.05$ \\
\hline \multicolumn{2}{|c|}{ Dermoid cyst } & $1(14.3 \%)$ & $12(12.9 \%)$ & $>0.05$ \\
\hline \multicolumn{2}{|c|}{ Hemorrhagic corpus luteum cyst } & $0(0.0 \%)$ & $9(9.7 \%)$ & $>0.05$ \\
\hline \multicolumn{2}{|c|}{ Fibroids } & $0(0.0 \%)$ & $6(6.5 \%)$ & $>0.05$ \\
\hline \multicolumn{2}{|c|}{ Ovarian cancer } & $2(28.6 \%)$ & $0(0.0 \%)$ & 0.004 \\
\hline \multicolumn{2}{|c|}{ Uterine cancer } & $2(28.6 \%)$ & $0(0.0 \%)$ & 0.004 \\
\hline \multicolumn{2}{|c|}{ Complications } & $3(42.9 \%)$ & $5(5.4 \%)$ & 0.010 \\
\hline \multicolumn{2}{|c|}{ Ascites } & $0(0.0 \%)$ & $4(4.3 \%)$ & $>0.05$ \\
\hline \multicolumn{2}{|c|}{ Hospital stay (days) } & $6.4 \pm 3.4$ & $2.8 \pm 0.2$ & $<0.001$ \\
\hline
\end{tabular}

\section{DISCUSSION}

In our study, mean age of patients was 45 years (range from $18 \mathrm{y}$ to $71 \mathrm{y}$.), Mean weight was $73.1 \mathrm{~kg}$, of height was $1.66 \mathrm{~m}$ and of BMI was $26.6 \mathrm{~kg} / \mathrm{m} 2$. Postmenopause was in $40.0 \%$ of cases. Premenopause were $60 \%$ of cases. 
Minority of cases $(7.0 \%)$ underwent laparotomy. Mean \pm SD of operation duration was $134.4 \pm 45.6$ minutes, while of blood loss was $309.4 \pm 192.7 \mathrm{~mL}$, The most frequent pathology was endometriosis (34.0\%), followed by serous cyst $(20.0 \%)$, tubo-ovarian complex (13.0\%), dermoid cyst $(13.0 \%)$, hemorrhagic corpus luteum cyst $(9.0 \%)$, fibroids $(6.0 \%)$, ovarian cancer $(2.0 \%)$ and uterine cancer $(2.0 \%)$. Complications were in $8.0 \%$, and whole ascites developed in (4.0\%). Mean \pm SD of hospital stay was $3.1 \pm 1.6$ days.

The most frequent clinical presentations were abdominal pain $(67.0 \%)$, followed by pelvic pain $(53.0 \%)$, then bleeding $(30.0 \%)$ and urinary symptoms $(25.0 \%)$

The increased risk for the rupture of the mass and spillage of cyst contents remains the most reported complication providing an important disadvantage of the method. On the contrary, a debate exists there, because according to the current literature it is not clearly reported which is the estimated risk of rupture during laparotomy, since surgeons seldom refer to the risk of rupturing a cyst when it is removed by laparotomy (Matsushita et al., 2014).

This suspicion is not supported by several investigators that report the intact cystectomy by laparoscopy in rates up to 80\% (Djukic et al., 2014), or similar rates when laparoscopy and laparotomy are compared. Djukic et al. (2014) report that the cyst was removed enraptured in $72,2 \%$ of the cases, something that is comparable to the $68 \%$ of our study. Many surgeons first puncture cysts after putting them in the endobag, but this is not a general rule.
While, in contrary Mettler et al. (2011) a study was carried out on 641 pt., 493 $(76.9 \%)$ ovarian tumors were treated laparoscopically and $138(21.5 \%)$ by laparotomy. While in our study only $7 \%$ are converted to laparotomy either due to severe adhesions or malignancies diagnosed by Frozen Section Biopsy. We explain that due to the technical progress in laparoscopy used tools and increased experiences in dealing with complications or tumours.

In addition to that, in their study twelve laparoscopies were converted to laparotomy, six because of technical reasons such as severe adhesions, bleeding, or tumor size, and six for intraoperative suspicion of malignancy. While in our Study suspicion of malignancy was managed Laparoscopically and Frozen Section Biopsy was taken which guided us how to proceed in management according to the referred pathology.

Dodge et al. (2012) Stated that, laparoscopy is a reasonable alternative to laparotomy, provided that appropriate surgery and staging can be done. The choice between laparoscopy and laparotomy should be based on patient and clinician preference. Discussion with a gynecologic oncologist is recommended.

The first controversial issue regarding laparoscopic surgery for the treatment of ovarian cancer is the accuracy of laparoscopic surgical staging. Among patients with surgical stage I ovarian cancer, those who have undergone comprehensive surgical staging have a lower risk of recurrence than do those who have not. It has been argued that laparoscopy does not allow for a thorough 
inspection of the pelvis, mesentery, and peritoneum leading to failure of upstaging and in adequate administration of chemotherapy (Ghezzi et al., 2010). Alternative evaluations of the accuracy of comprehensive surgical staging can be inferred by comparing the rate of upstaging and lymph node yield between laparoscopic and laparotomic cases. A case-control series of 34 patients showed no difference in the lymph node yield between laparoscopy and laparotomy. Additionally, a meta-analysis of 3 comparative studies revealed no significant difference between the upstaging rates of laparoscopy and laparotomy (Park et al., 2013). Likewise, in the present study, there were no significant differences in the upstaging rate or lymph node yield between the 2 groups.

The second controversial issue is the rate of tumor rupture between the laparoscopic and laparotomic approaches and the prognostic value of tumor rupture during surgery. In general, reported tumor rupture rates range from $11.4 \%$ to $30.3 \%$. However, the risk of tumor rupture is not only limited to laparoscopic surgery, and some studies have reported that the risk of tumor rupture is similar between laparoscopic and laparotomic surgery. One previous study reported that the incidence of tumor rupture in patients with ovarian cancer was similar between the laparoscopy and laparotomy groups $(10.5 \%$ versus $12.1 \%$, respectively; P1/41.000) (Park et al., 2010).

Other studies demonstrated that the rate of tumor rupture was $8 \%$ in both procedures (Suh et al., 2010 and Tozzi \& Schneider, 2010). The clinical significance of tumor rupture during surgery remains uncertain. The largest study of cyst rupture was a retrospective, multicenter study involving $>1500$ patients. The study demonstrated that tumor rupture was an independent predictor of disease-free survival. In contrast, no difference in survival was noted in a retrospective review of 394 patients. However, these findings have not been confirmed in prospective studies. The prognostic value of intraoperative tumor rupture must be more clearly examined based on large-scale randomized controlled trials (RCTs) in patients with early ovarian cancer (Park et al., 2013). All efforts should be made to reduce the incidence of tumor contamination of the abdominal cavity, including liberal use of a laparoscopic bag, controlled aspiration, and minimization of the risk of rupture (Sternchos et al., 2013).

In the present study, thorough irrigation of the intraperitoneal cavity was performed using distilled water and cisplatin at the end of the surgical procedure, which may have reduced the negative impact of potential tumor rupture on recurrence and survival. Intraperitoneal administration of anticancer drugs has many pharmacokinetic advantages and induces high response rates in the abdomen because the "peritoneal plasma barrier" provides dose-intensive therapy (Cascales-Campos et al., 2014).

The third point of controversy is portsite metastasis. Large series of patients with malignant disease undergoing transperitoneal laparoscopy suggested that the incidence of port site implantation was $<1 \%$ (Abu-Rustum et al., 2010). 
Zivanovic et al. (2012) reported that the port site recurrence rate of $1.96 \%$ following laparoscopy for ovarian, fallopian tube, or primary peritoneal cancer among 796 patients was comparable with the wound recurrence rate following laparotomy.

Nezhat et al. (2010) found that the rate of port-site metastasis in laparoscopic management of ovarian cancer was not higher than that in laparotomicmanagement. The precise origin of port-site metastasis remains unclear. Several mechanisms of the development of port-site metastasis have been proposed. Among the most common are hematogenous spread, direct wound contamination and implantation, multiple effects of pneumoperitoneum, the effects of the gases used for insufflation, the "chimney effect," aerosolization of tumor cells, local immune reactions, and the surgical technique used (Abu-Rustum et al., 2010).

We observed no port-site metastasis in the present study. We placed a pipe in the vaginal canal and removed the specimen from the pipe through the vaginal canal to avoid contact with the vaginal wall; the vaginal was then thoroughly irrigated before suturing.

The fourth point of controversy is the efficiency of laparoscopic staging compared with that of traditional laparotomic procedures. Standard survival outcomes must not be compromised for a procedure to be accepted as the standard treatment for early ovarian carcinoma. In agreement with this, we found no significant differences in survival analyses based on surgical management approaches. The overall and 5-year survival rates were $92.9 \%$ and $91.3 \%$ in the laparoscopy group and $90.0 \%$ and $88.4 \%$ in the laparotomy group. Ghezzi et al. (2012) reported the largest study to date of laparoscopically managed early ovarian cancer. In their prospective study of 82 patients with a median follow-up time of 28.5 (range, 3-86) months, the overall and disease-free survival rates were $98.8 \%$ and $95.1 \%$, respectively.

\section{CONCLUSION}

Laparoscopic surgery seemed to offer significant advantages such as reduced hospital stay, less adverse effects, and better quality of life and due to that reasons, laparoscopic surgery became a corner stone in management of adnexal masses either benign or malignant especially if the facility of Frozen Section Biopsy can be offered.

\section{REFERENCES}

1. Abu-Rustum NR, Rhee EH, Chi DS, Sonoda Y, Gemignani M and Barakat RR. (2010): Subcutaneous tumor implantation after laparoscopic procedures in women with malignant disease. Obstetrics \& Gynecology, 103(3):480-7.

2. Cascales-Campos PA, Gil J, Gil E, Feliciangeli E, González-Gil A, Parrilla JJ and Parrilla P. (2014): Treatment of microscopic disease with hyperthermic intraoperative intraperitoneal chemotherapy after complete cytoreduction improves disease-free survival in patients with stage IIIC/IV ovarian cancer. Annals of Surgical Oncology, 21(7):2383-9.

3. Djukic M, Stankovic Z, Vasiljevic M, Savic D, Lukac B and Djuricic S. (2014): Laparoscopic management of ovarian benign masses. Clinical and Experimental Obstetrics \& Gynecology, 41(3):296-299.

4. Dodge JE, Covens AL, Lacchetti C, Elit LM, Le T, Devries-Aboud $M$ and FungKee-Fung M. (2012): Management of a 
suspicious adnexal mass: a clinical practice guideline. Current Oncology, 19(4): 244-249.

5. Ghezzi F, Cromi A, Uccella S, Bergamini V, Tomera S, Franchi $M$ and Bolis P. (2010): Laparoscopy versus laparotomy for the surgical management of apparent early stage ovarian cancer. Gynecologic Oncology, 105(2):409-13.

6. Ghezzi F, Malzoni M, Vizza E, Cromi A, Perone C, Corrado G, Uccella S, Cosentino F, Mancini E and Franchi M. (2012): Laparoscopic staging of early ovarian cancer: results of a multi-institutional cohort study. Annals of Surgical Oncology, 19(5):1589-94.

7. Grammatikakis I, Trompoukis P, Zervoudis S, Mavrelos C, Economides $\mathbf{P}$ and Tziortzioti V. (2015): Laparoscopic treatment of 1522 adnexal masses: an 8-year experience. Diagnos Therapeu Endosc., 1(5): 15-30.

8. Karnik A, Tembey RA and Mani S. (2015): Value of MRI in characterizing adnexal masses. J Obstet Gynecol India, 65(4):259-66.

9. Matsushita H, Watanabe K, Yokoi T and Wakatsuki A. (2014): Unexpected ovarian malignancy following laparoscopic excision of adnexal masses. Human Reprod., 29(9):1912-7.

10. Mettler L, Jacobs V, Brandenburg K, Jonat W and Semm K. (2011): Laparoscopic management of 641 adnexal tumors in Kiel, Germany. The Journal of the American Association of Gynecologic Laparoscopists, 8(1):74-82.

11. Nezhat FR, Ezzati M, Chuang L, Shamshirsaz AA, Rahaman J and Gretz $H$. (2010): Laparoscopic management of early ovarian and fallopian tube cancers: surgical and survival outcome. American Journal of Obstetrics and Gynecology, 200(1):83-84.
12. Park JY, Kim DY, Suh DS, Kim JH, Kim YM, Kim YT and Nam JH. (2010): Comparison of laparoscopy and laparotomy in surgical staging of early-stage ovarian and fallopian tubal cancer. Annals of Surgical Oncology, 15(7):2012.

13. Park HJ, Kim DW, Yim GW, Nam EJ, Kim S and Kim YT. (2013): Staging laparoscopy for the management of early-stage ovarian cancer: a metaanalysis. American Journal of Obstetrics and Gynecology, 209(1):58-63.

14. Sternchos J, Finger T, Mahdavi A. Nezhat C, Nezhat $F$ and Nezhat C. (2013): Laparoscopic management of ovarian, fallopian tube and primary peritoneal cancer. Nezhat's Video-Assisted and Robotic-Assisted Laparoscopy and Hysteroscopy, 4th ed., Pbl. Cambridge, MA: Cambridge University Press; Pp. 508-525.

15. Suh KS, Park SW, Castro A, Patel H, Blake P, Liang $M$ and Goy A. (2010): Ovarian cancer biomarkers for molecular biosensors and translational medicine. Expert review of Molecular Diagnostics, 10(8):1069-83.

16. Tozzi $R$ and Schneider A (2010): Laparoscopic treatment of early ovarian cancer. Current Opinion in Obstetrics and Gynecology, 17(4):354-8.

17. Zaman S, Majid S, Hussain M, Chughtai O, Mahboob J and Chughtai S. (2010): A retrospective study of ovarian tumours and tumour-like lesions. J Ayub Med Coll Abbottabad, 22(1):104-8.

18. Zivanovic O, Sonoda Y, Diaz JP, Levine DA, Brown CL, Chi DS, Barakat RR and Abu-Rustum NR. (2012): The rate of portsite metastases after 2251 laparoscopic procedures in women with underlying malignant disease. Gynecologic Oncology, 111(3):431-7. 
دور المنظار الجراحي في تشخيص وعلاج الأورام الموجودة

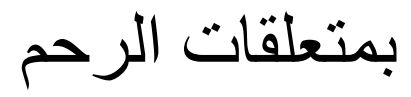

إبراهيم صفوت إبراهيم، إسماعيل طلعت الجارحي، ماجد محمد لبيب

قسم النساء والتوليد، كلية الطب، جامعة الأزهر

E-mail: dribrahimelqtaly89@gmail.com

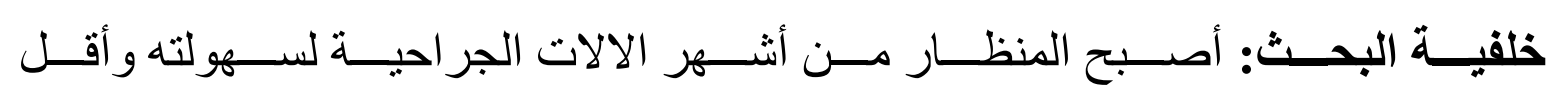

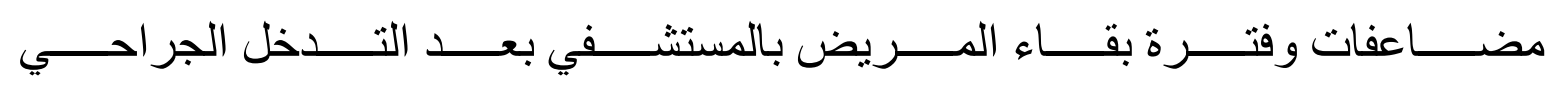

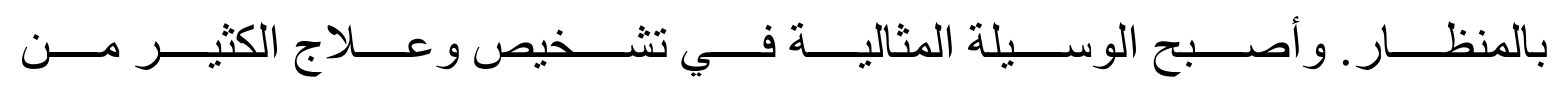
أمر اض النساءو والتوليد.

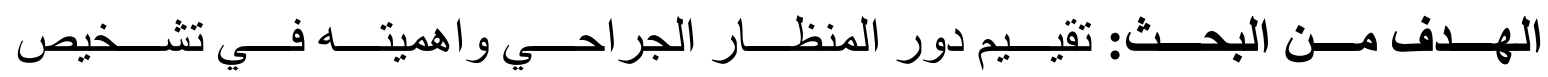
و علاج أور ام متعلقات الرحم.

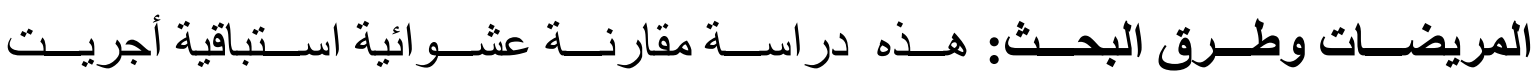

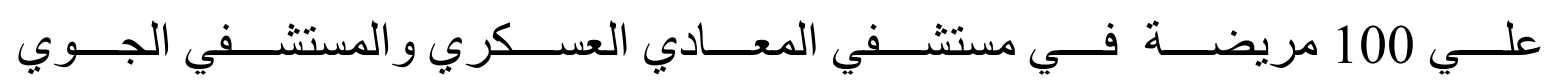

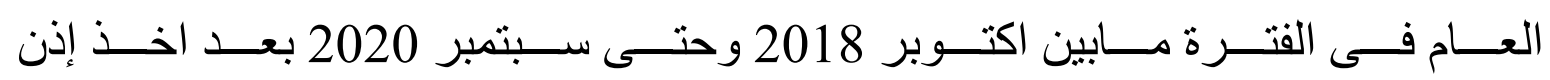

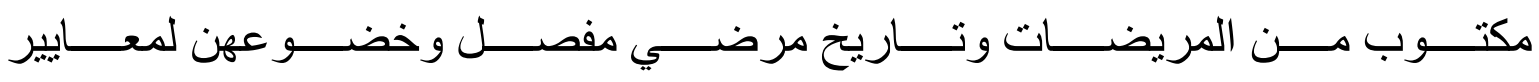

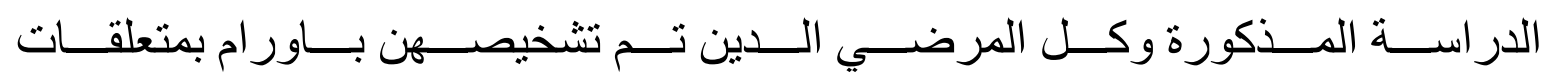

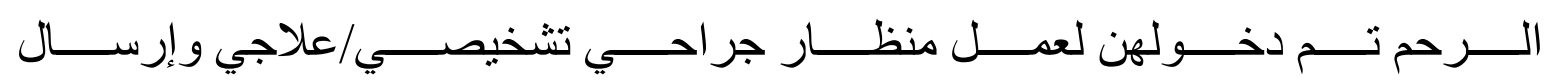
العينات إلي معمل التحليل الباثولوجي لدر لـاسة النتائج.

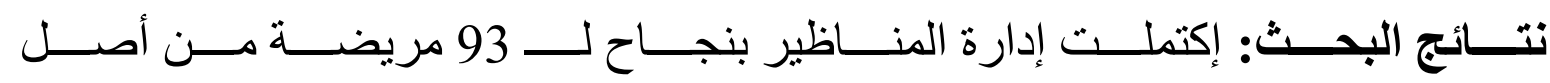

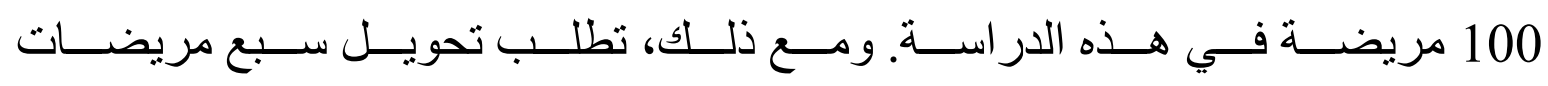

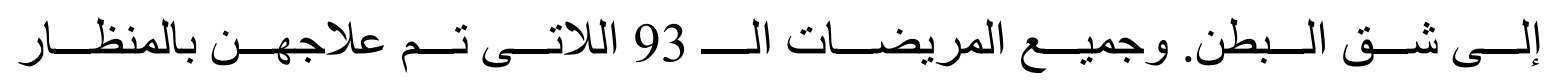

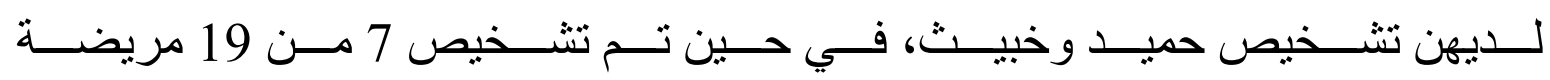

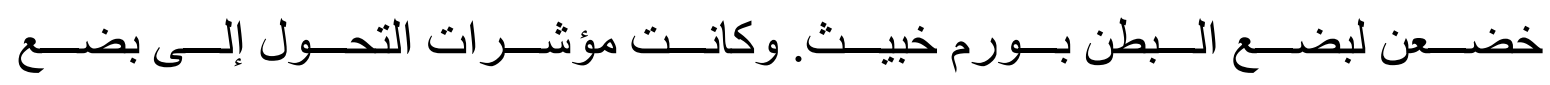




\section{LAPAROSCOPIC MANAGEMENT OF SUSPICIOS ADENEXAL MASS}

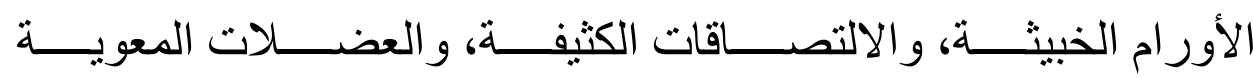

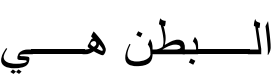

الدقبقة.

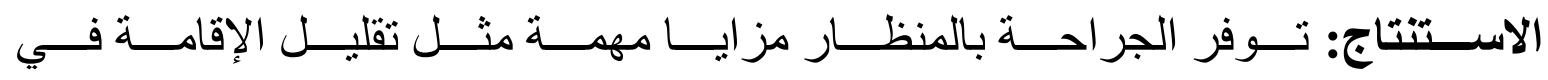

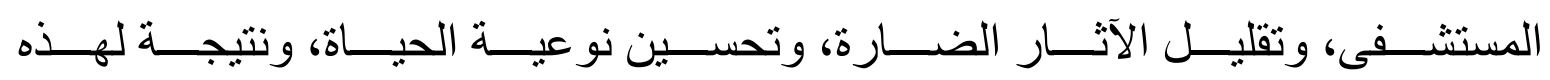

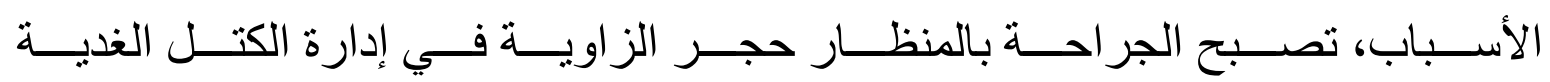

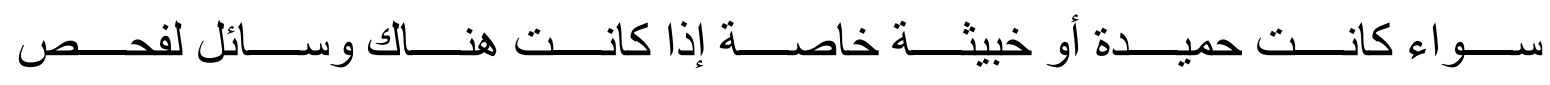
عبنات.

الكلمات الدالة : أور ام الرحم، منظار البطن، سرطان المبيض. 